\title{
Referências barrocas nos casulos de ouro de Hubert Duprat
}

\author{
Sandra Makowiecky ${ }^{1}$ \\ Luciane Ruschel Nascimento Garcez ${ }^{2}$
}

\begin{abstract}
RESUMO
Este artigo pretende comentar um trabalho do artista plástico francês, Hubert Duprat, seus Casulos, pequenas peças de ouro e pedras preciosas que o artista vem produzindo desde 1980. Busca-se fazer uma relação desta obra com a arte do período barroco, por suas conexões matéricas e conceituais; pelos paradoxos, pelo excesso, pela sofisticação desta arte, e pelo ouro.
\end{abstract}

PALAVRAS-CHAVE: ouro; arte barroca; Casulos.

"Em arte, tanto em pintura quanto em música, não se trata de reproduzir ou inventar formas, mas de captar forças. É por isso que nenhuma arte é figurativa".

Gilles Deleuze $e^{3}$

O artista plástico francês Hubert Duprat, em sua obra Casulos, trabalha com o que há de mais precioso na natureza: ouro, diamantes, pérolas, turquesas, corais, rubis, esmeraldas. Ele disponibiliza este material em aquários previamente preparados para que larvas tricópteras teçam seus casulos com este material. São larvas que vivem em rios e tecem seus casulos a partir do material que encontram no leito destes rios: folhas, conchas, pedaços de gravetos, etc. Duprat as coloca em aquários que têm seu fundo coberto de ouro e pedras preciosas, disponibilizando assim outra ordem de materiais para que estas larvas construam suas crisálidas como jóias.

O artista apresenta estes casulos como se fossem realmente jóias, em "caixas" com tampa de vidro, ficam expostos uns ao lado dos outros, assim como peças em joalherias.

\footnotetext{
${ }^{1}$ Orientadora; professora do Mestrado em Artes Visuais - Departamento de Artes Visuais - PPGAV - do Centro de Artes - UDESC.

${ }^{2}$ Mestranda regularmente matriculada no PPGAV-CEART, UDESC.

${ }^{3}$ DELEUZE, Gilles. Francis Bacon - Lógica da sensação. Rio de Janeiro: Jorge Zahar Editor, 2007. P. 62.
} 
Mas esta obra não é perene, como o artista não interfere no resultado final e as pepitas e pedras ficam conectadas por uma secreção que a larva expele formando sua crisálida, o casulo tem um tempo de vida; apesar de estar utilizando materiais não perecíveis, o processo faz com que a obra se desmanche em um tempo curto. Esta obra fala de paradoxos, o artista trabalha com um metal dos mais duráveis que existem, pedras que, sem a ação do homem, não têm tempo de vida determinado, e ainda assim sua obra não dura muito. $\mathrm{O}$ artista fala do efêmero na arte e na vida, fala da instabilidade e da fragilidade do que nos rodeia, de coisas a relações. Ao não interferir no produto final, Hubert Duprat prioriza o processo de criação da obra, o conceito que gerou este trabalho. Ao reaproveitar os materiais, e uma vez que ele vem fazendo este trabalho desde 1980, os Casulos de ouro se tornam um trabalho em série, reproduções sem original, cópias sem matriz.

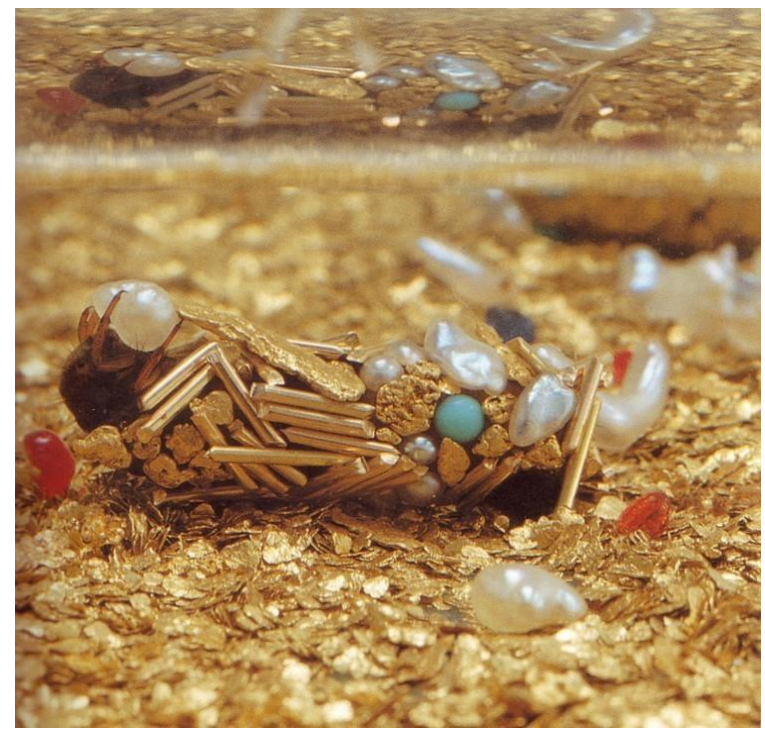

Hubert Duprat

Larvas e seus casulos. Imagem disponível em: BESSON, Christian (Org.). Hubert Duprat Theatrum - Guide imaginaire des collections. Collection reConnaître. Paris: Musée départemental (Digne), Philippe Grand, Antenne Éditoriale de Lyon, 2002.

Mas o aspecto formal destes casulos remete a outras temporalidades, outras obras. $\mathrm{O}$ conjunto formado pelas pepitas, turquesas, pérolas, trazem o excesso à mente. Mas é um excesso que fala da sofisticação, do esplendor. Remetem a uma arte onde estas qualidades estavam inerentes à obra: a arte barroca. Questões como a instabilidade nas relações, a fragilidade dos valores humanos, a repetição, são também passíveis de serem relacionados aos casulos de ouro de Hubert Duprat e ao período barroco. 


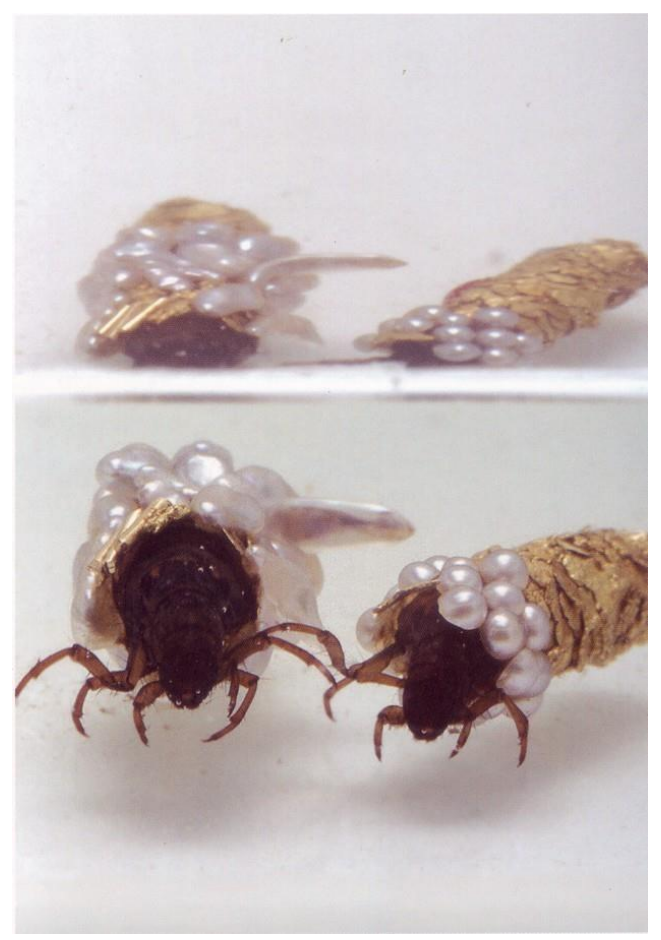

\section{Hubert Duprat}

Larvas e seus casulos. Imagem disponível em: BESSON, Christian (Org.). Hubert Duprat Theatrum - Guide imaginaire des collections. Collection reConnaître. Paris: Musée départemental (Digne), Philippe Grand, Antenne Éditoriale de Lyon, 2002.

A arte barroca fez uso corrente do ouro como material plástico; no Brasil, retábulos e o interior de igrejas eram recobertos deste metal reluzente. A sensação de irrealidade, ou de miragem, provocada por esta profusão de ornatos reluzentes na "igreja toda de ouro" configura a bem-sucedida realização do objetivo barroco, levado aqui à sua conclusão lógica de desintegrar os contornos estruturais e dissolver os padrões de referência. Os retábulos, com seus minuciosos entalhes e rico revestimento dourado, atrai o olhar magneticamente, ampliando o espaço e dissolvendo seus limites, com sugestões de vibração e movimento (BURY, 2006). O ouro no barroco brasileiro, assim como na Europa, cumprindo seu papel educativo e missionário, quando, após o processo de Reformas Religiosas, ocorrido no século XVI, a Igreja Católica havia perdido muito espaço e poder, buscava continuar influenciando o cenário político, econômico e religioso na Europa. A arte barroca surge neste contexto e expressa todo o contraste deste período: a espiritualidade e teocentrismo da Idade Média com o racionalismo e antropocentrismo do Renascimento. 


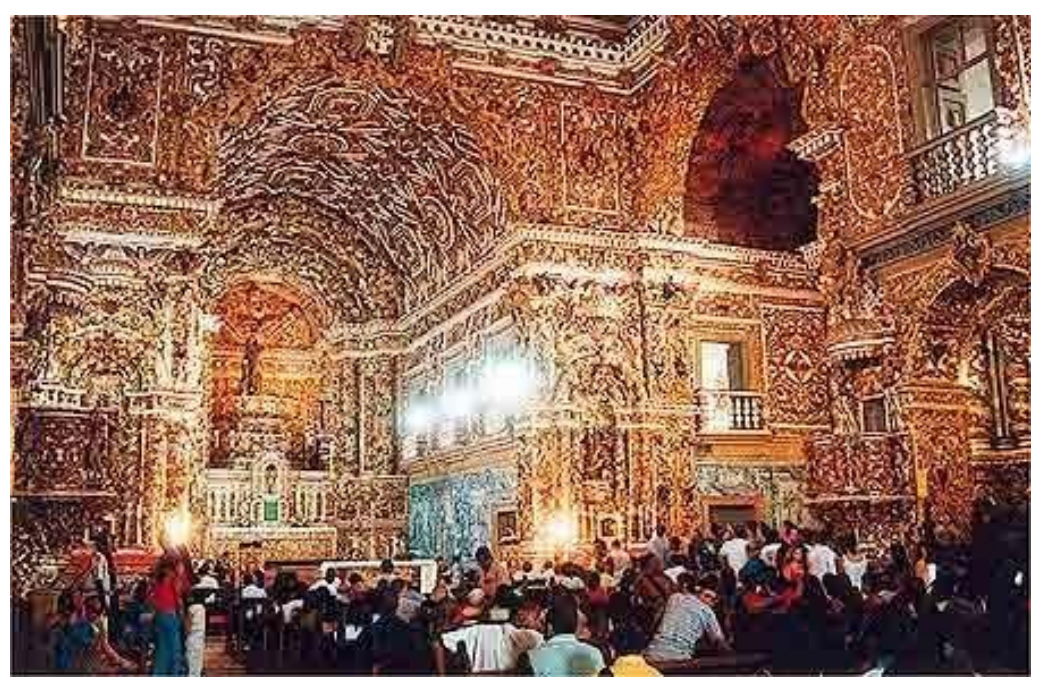

Igreja e Convento de São Francisco, Salvador, Bahia: considerada uma das mais ricas e espetaculares igrejas do país, tem todo o interior coberto em ouro. Disponível em http://www.starnews2001.com.br/Aleijadinho/barroco_brasileiro.html. Acesso em 12 jul. 2008.

Para além da origem do termo "barruec" (BAZIN, 1993, p.1) associado a algo que fugia dos padrões normais (uma pérola imperfeita), o barroco passou a designar nas artes o “pecado da divergência” em relação ao ideal clássico da Renascença (GOMBRICH, 1990, p.109) e, por extensão, uma arte menor que desvirtuava o belo e o exato em favor de um virtuosismo exagerado e desmedido por parte dos artistas. Propenso à evasão, o artista barroco prefere "formas que alçam vôo" às que são estáticas e densas (BAZIN, 1993, p. 2).

A arte barroca originou-se na Itália (séc. XVII), mas não tardou a irradiar-se por outros países da Europa e a chegar também ao continente americano, trazida pelos colonizadores portugueses e espanhóis. O barroco apresenta características regionais nas diferentes localidades em que se desenvolveu, sendo também regional, individual e subjetivo. As obras barrocas romperam o equilíbrio entre o sentimento e a razão ou entre a arte e a ciência; na arte barroca predominam as emoções e não o racionalismo da arte renascentista. É uma época de conflitos espirituais e religiosos. O estilo barroco traduz a tentativa angustiante de conciliar forças antagônicas: bem e mal; Deus e Diabo; céu e terra; pureza e pecado; alegria e tristeza; paganismo e cristianismo; espírito e matéria. 


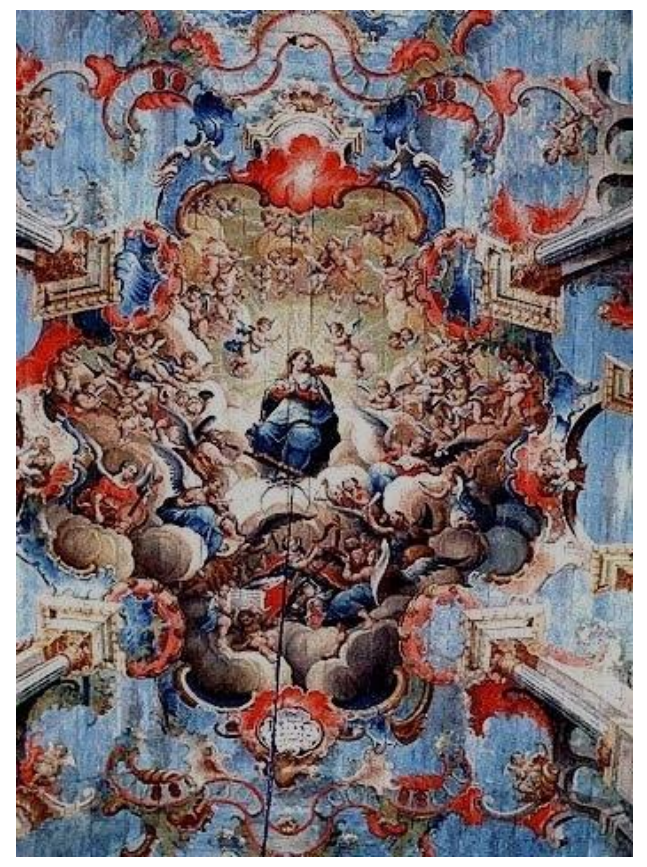

Painel do teto da Igreja de São Francisco de Assis, Manuel da Costa Athayde.Ouro Preto. Trompe l'oeil. Disponível em http://www.starnews2001.com.br/Aleijadinho/sao-francisco.htm Acesso em 12 jul. 2008.

Consequentemente, na arte barroca irão predominar características como: predomínio do emocional sobre o racional pautado em seu propósito de impressionar os sentidos do observador, baseando-se no princípio segundo o qual a fé deveria ser atingida através dos sentidos e da emoção e não apenas pelo raciocínio; a busca de efeitos decorativos e visuais, através de curvas, contracurvas, colunas retorcidas; o entrelaçamento entre a arquitetura e escultura; a presença de violentos contrastes de luz e sombra; a pintura com efeitos ilusionistas. As obras dos artistas barrocos europeus valorizam as cores, as sombras e a luz, e representam os contrates. As imagens não são tão centralizadas quanto as renascentistas e aparecem de forma dinâmica, valorizando o movimento. Muitos artistas barrocos dedicaram-se a decorar igrejas com esculturas e pinturas, utilizando a técnica da perspectiva e o trompe-l'oeil, a ilusão, que é a tentativa de buscar nesse espaço angustiante algo que o transcenda; então se busca a ilusão como uma forma de, sem poder mais negar a nova realidade, criar uma nova fantasia dentro de um espaço real que não pode negar nem, tranqüilamente, assimilar.

O artista fica livre de qualquer regra ou padrão para liberdade de criação; busca de efeitos decorativos e visuais; composição dinâmica; a estreita relação das artes, através da arquitetura e escultura intimamente ligadas; valorização do entalhe na construção de altares, 
com luxo na decoração e aplicação a ouro; pintura de tetos com efeitos ilusionistas; fachadas simples, contraste entre a simplicidade do exterior com a opulência decorativa do interior, era a tônica na arquitetura. Em uma palavra: excesso. É uma arte que lida fortemente com a sensação, a ativação de todos os sentidos.

Hubert Duprat também trabalha com a sensação, e é desta forma que o espectador percebe sua obra. Como cita o teórico francês Gilles Deleuze:

\begin{abstract}
Vibrar a sensação - acoplar a sensação - abrir ou fender, esvaziar a sensação. A escultura apresenta esses tipos quase em estado puro, com suas sensações de pedra, de mármore ou de metal, que vibram segundo a ordem dos tempos fortes e dos tempos fracos, das saliências ou das reentrâncias, seus poderosos corpo-a-corpo que os entrelaçam, seu arranjo de grandes vazios ente um gruo e outro e no interior de um mesmo grupo, onde não mais se sabe se é a luz, se é o ar que esculpe ou é esculpido (2007, p. 219).
\end{abstract}

O autor está falando da sensação que é o que sustenta um trabalho como obra de arte. A força com que o artista cria e a percepção desta pelo espectador. O que está em jogo é a sensação que a obra mantém em si, e que sobrevive através dos tempos, é a sensação que retorna. Provavelmente é esta mesma sensação que a pessoa percebe quando entra em uma igreja reluzente de ouro. Excessos que na arte são permitidos, liberdades que são o fruto dessa vontade de arte, que legitima todos os arroubos da imaginação. O homem quer fazer da Casa de Deus tudo aquilo que não ousa na sua própria morada, ele a deseja grande, rica, deslumbrante e simbólica do Poder Divino. Fala-se aqui da sensação, sentimento de reverência do espectador que está em um ambiente dito sagrado; este temor, esta reverência frente ao esplendor são recorrentes ao longo da história, é um sintoma que se observa na arte, é uma sensação que permanece e retorna em sua forma mais pura frente à obra de arte.

Gilles Deleuze (2007) diz que o cristianismo submeteu a forma a uma "deformação fundamental, na medida em que Deus se encarnava, se crucificava, descia e subia aos céus etc. A forma ou a Figura não eram mais exatamente remetidas à essência, mas ao que é em princípio o seu contrário, o acontecimento, e até mesmo o mutável, o acidente” (p. 125). O autor está comentando sobre o caráter educativo desta arte a serviço da igreja, que para este fim usou-se do excesso do dourado, um paraíso que está à espera daquele que se arrepende. Há muito que o ouro tem caráter simbólico e sagrado, já na arte egípcia antiga se acreditava 
que a pele dos deuses era de ouro, o brilho dourado era sinônimo de sagrado. $\mathrm{Na}$ arte bizantina traduzia o esplendor do clero e do império. No barroco este recurso foi amplamente difundido.

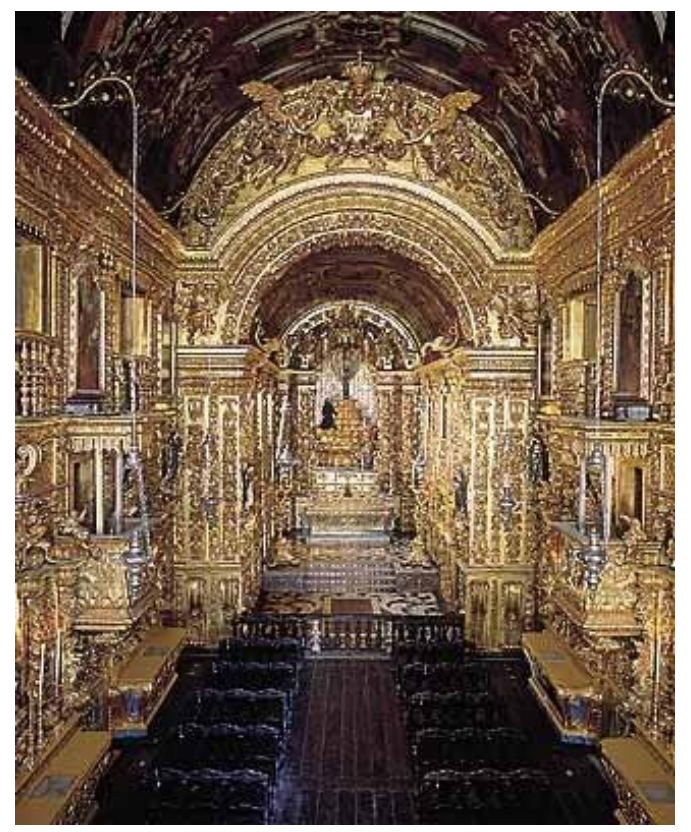

Igreja da Ordem Terceira de São Francisco da Penitência, do Rio de Janeiro. Disponível em http://www.starnews2001.com.br/Aleijadinho/ordem-terceira.html. Acesso em 12 jul. 2008.

Foi a arte do excesso, da ostentação. Cumpriu sua função durante certo tempo, não conseguiu se manter às mudanças políticas e sociais que eventualmente tomaram conta do mundo ocidental. Na ânsia de catequizar o indivíduo a arte foi a maior aliada da Igreja; enquanto que no período da Renascença esta serviu de registro de uma realidade que começava a se transformar, onde o homem passou a ser o centro do mundo, a religião cumpria seu papel de orientação espiritual, mas também teve grande influência política e econômica. Dentro deste cenário, encontra-se a arte como uma das principais ferramentas, registrando os horizontes que dia-a-dia se ampliavam, servindo à Igreja, a Deus e ao homem burguês que crescia em prestígio na sociedade e, também à nobreza, que fez do artista uma profissão de respeito e do talento uma inspiração divina.

A Europa do século XVII vivia a consolidação de uma nova realidade, que dizia respeito não só à vida material, social, econômica, mas também às coisas do espírito, da subjetividade. Ocorria, então, uma sutil mudança no modo de os homens letrados encararem tanto o ver-o-mundo quanto o 
estar-no-mundo. Esse conflito é que está estampado nas obras barrocas, em sua grande maioria. Não se trata de questionar a existência de Deus, mas sim de se ter uma nova postura frente às coisas do espírito, já que o ser humano passou a se enxergar como um microcosmo repleto de vícios e desejos que precisava combater antes de louvar a Deus (SANSEVERO, 2007).

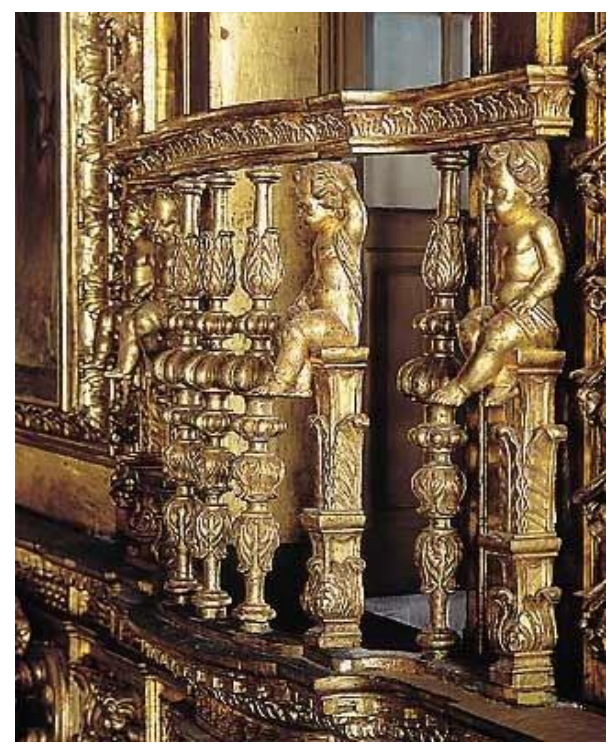

Detalhe. Igreja da Ordem Terceira de São Francisco da Penitência, do Rio de Janeiro. Disponível em http://www.starnews2001.com.br/Aleijadinho/ordem-terceira.html. Acesso em 12 jul. 2008.

Em Renascença e Barroco, Wölfflin deixa explícito que há uma oposição bem demarcada entre o estilo renascentista e o barroco. Ele atribui ao primeiro uma "beleza tranqüila", que causa um "bem-estar geral", enquanto que o segundo domina o espectador com o "poder da emoção", causando um turbilhão "imediato e avassalador" (1989, p.47). Wölfflin foi o primeiro a perceber que o artista barroco "não evoca a plenitude do ser, mas o devir, o acontecer; não a satisfação, mas a insatisfação e a instabilidade" (1989, p. 48). "Como a característica principal do estilo pictórico é justamente o contraste entre luz e sombra, o que ele vai trabalhar, na verdade, é a massa e a matéria. E a matéria representa, por essência, a própria carne e seus desejos" (SANSEVERO, 2007).

A partir deste período, a arte rapidamente toma outros rumos, do exagero do Barroco às excentricidades de quem não sabe mais o que acontece naquele mundo antes tão organizado, do Maneirismo a imagem passa por diversos processos, modificações de concepção e forma que refletiam a sociedade vigente. Quando fala do barroco, o historiador Severo Sarduy vai além do que costumamos associar a este período. Para ele: 
O Barroco estava destinado, desde o seu nascimento, à ambigüidade, à difusão semântica. (...) Nódulo geológico, construção móvel e lamacenta, de barro, pauta da dedução ou pérola; dessa aglutinação, dessa proliferação incontrolada de significantes, e também dessa firme orientação de pensamento, necessitava, para confrontar os argumentos reformistas, o Concílio de Trento. A esta necessidade respondeu a iconografia pedagógica proposta pelos jesuítas, uma arte literalmente do trompe-à-l'oeil, que pusesse a serviço do ensino, da fé, todos os meios possíveis, que negasse a discrição, o matiz progressivo do sfumato, para adotar a nitidez teatral, o repentino recorte do claro-escuro, e abandonasse a sutileza simbólica encarnada pelos santos, com seus atributos, para adotar uma retórica do demonstrativo e do evidente, pontuada de pés de mendigos e de farrapos, de virgens campesinas e mãos calosas. (...)

...explosão que provoca uma verdadeira cisão no pensamento, um corte epistemológico cujas manifestações são simultâneas e explícitas (1979, p. $57-58)$.

É nesta clave do exagero que Sarduy situa o movimento barroco, sendo que não foi um movimento extinto, é uma demonstração que se pode identificar na arte desde então.

Deleuze discorre sobre a arte como manifestação de um algo mais: "A arte pode, então, ser figurativa, mas vê-se com clareza que ela não o é inicialmente, que a figuração é apenas um resultado" (2007, p. 126). O resultado é o que implica a devoção de uma arte a serviço de Deus. Sobre o efeito deste excesso, pode-se dizer que: "Pois, ao mesmo tempo que ele rompe com a visão 'háptica' e com a visão próxima, ele não é simplesmente visual, mas se refere a valores tácteis, mesmo que os subordine à visão" (2007, p. 126-127). Estes "valores tácteis" de que o autor está falando podem ser encontrados nestes retábulos recobertos de ouro, e também nos casulos, ambos recorrem à sensação da mão que pode sentir, o ouro traz esta percepção.

Deleuze em A dobra: Leibniz e o barroco (1991) esclarece que, na perspectiva leibniziana, o objeto barroco se diferencia de seus antecessores justamente por tornar-se um acontecimento, e desprender-se da concepção quantitativa da História.

No Barroco, a alma tem com o corpo uma relação complexa: sempre inseparável do corpo, ela encontra nele uma animalidade que a atordoa, que a trava nas redobras da matéria, mas nele encontra também uma humanidade orgânica ou cerebral (o grau de desenvolvimento) que lhe permite elevar-se e que a fará ascender a dobras totalmente distintas (DELEUZE, 1991, p. 26). 


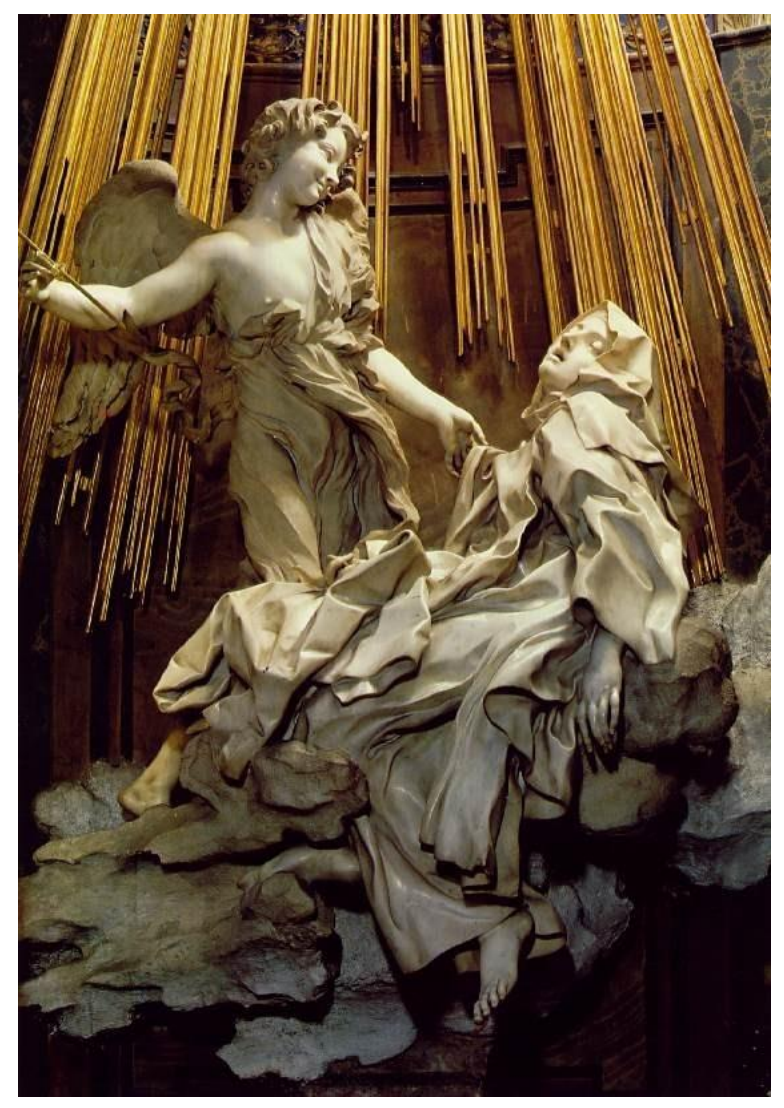

O êxtase de Santa Teresa de Bernini. Disponível em http://www.artchive.com/artchive/b/bernini/teresa.jpg. Acesso em 12 jul.2008

Para este autor, a perspectiva barroca independe do sujeito, já que aquilo que a determina é o ponto de vista, o local a partir do qual qualquer sujeito pode observar o objeto barroco e apreendê-lo. E como o que importa realmente é o ponto de vista, o artista do período barroco coloca sua representação pessoal do desejo sob a possibilidade de ser admirada, interpretada e avaliada por toda a humanidade. Desse modo, a dobra barroca se torna também a dobra do desejo, e por serem ilimitadas as possibilidades de redobramentos e desdobramentos, esse desejo se lança ao infinito, ao devir.

Pensar estas obras, tanto as obras do período barroco como os Casulos de Duprat, implica em pensar uma história da arte não através de rótulos e em diacronia, mas sim considerar as questões que reverberam, que sobrevivem. Como bem cita o teórico Georges Didi-Huberman: 
Diante de uma imagem - tão recente, tão contemporânea como seja - o passado não cessa nunca de reconfigurar-se, posto que esta imagem só se torna pensável em uma construção da memória, quando não da obsessão. Enfim, diante de uma imagem, temos que humildemente reconhecer o seguinte: que provavelmente ela nos sobreviverá, que diante dela somos o elemento frágil, o elemento do passado, e que diante de nós ela é o elemento do futuro, o elemento da duração. A imagem, a miúde, tem mais de memória e mais de porvir que o ser que a olha (2006, p. 12).

Em um outro livro deste teórico, O que vemos, o que nos olha, Didi-Huberman diz que não só se olha a obra, mas que esta também nos olha de volta, que neste momento abrese uma "fenda" no tempo, onde a obra é legitimada como arte, neste instante ela vive novamente, fala, respira, é neste instante que se reconhece sua potência como imagem. Nesta fenda também é possível ler o anacronismo, onde ela é contaminada por outras temporalidades, é neste instante em que a obra "nos olha" que é criada uma rede de sensações, que é o que dá sentido à arte. Imagem como cintilação, como gesto.

Uma imagem não pode ser reduzida ao objeto que ela tenta representar, ela é, antes de tudo, uma intenção, neste caso uma intenção cheia de significados. Os casulos de Duprat assumem que mostram a possibilidade da dissimulação e do desvio contido na representação, exibindo sua dualidade e maravilhando o espectador com suas possibilidades e questionamentos. Seus casulos preciosos, objetos miméticos da natureza, se tornam exemplos de arte barroca, de acúmulo e ostentação. Segundo Éric Audinet, há em seu trabalho uma tentativa de captar a luz que recai sobre o universo, mesmo na escuridão de seu atelier onde as larvas produzem seus casulos; provêm de uma necessidade de espaço e tempo em uma época em que o que se vê é o crepúsculo (AUDINET, 1986). Luz que também foi buscada nas Igrejas de ouro do barroco.

Obter a luz, mas também seu desvio, é tornar visível o real, desenvolver o mecanismo de aparição das imagens e as liberar ao tempo, às imprevisíveis inflexões do dia, da luz. Estas construções, mini-esculturas preciosas, fabricadas por larvas repugnantes, são o verdadeiro exemplo do desvio. De uma só vez estas criaturas são máquinas de captar luz, luz esta que provém de pérolas, ouro e diamantes. Seus casulos são objetos complexos, na verdade não são figuras. Ao contrário, pode-se dizer que são a máscara, a manifestação de uma deturpação da paisagem. É como se o acesso à realidade precisasse de uma mediação, um intermediário. Os casulos de Duprat são micro-paisagens barrocas, onde tudo 
é falso, têm seus sentidos e objetivos trocados, menos a preciosidade que está presente e é gritante.

A bipolaridade presente em seu trabalho pode ser pensada com Caillois, quando este diz que:

\footnotetext{
Não há no universo nada que não seja suscetível de formar uma oposição bipartida e que não possa então simbolizar as diferentes manifestações acopladas e antagônicas do puro e do impuro, das energias renovadoras e das forças da morte, dos pólos atrativo e repulsivo do mundo religioso (2004, p. 40).
}

Omar Calabrese (1988), ao avaliar a contemporaneidade e rotulá-la como "Idade Neobarroca", procura analisar vários aspectos de nossa sociedade através de nove pares conceituais, como ritmo/repetição, limite/excesso, pormenor/fragmento, instabilidade/metamorfose, desordem/caos, nó/labirinto, complexidade/dissipação, quase/ não-sei-quê e distorção/perversão. Mas os pares conceituais de Calabrese, ao contrário dos de Wölfflin, não comportam oposições intrínsecas, mas sim complementaridades, que nos remetem a uma série de questionamentos interessantes, como por exemplo: a multiplicidade que a fragmentação de nosso tempo acarreta poderia ser uma característica intrínseca ao Barroco? A bipolaridade dos casulos pode ser uma característica barroca, aliada ao luxo e exagero dos materiais? São questões que ficam para pensar.

\section{REFERÊNCIAS:}

AUDINET, E. L'Envers du Paysage et Entretien avec Hubert Duprat. In Magazine, n. 2, Galerie Images Nouvelles/Jean-François Dumont, Bordeaux, février 1986.

BAZIN, G. Barroco e Rococó. São Paulo: Martins Fontes, 1993.

BURY, J. Arquitetura e arte no Brasil colonial. RIBEIRO, Myriam A. (org.). Brasília, DF: IPHAN/MONUMENTA, 2006.

CAILLOIS, R. El Hombre y lo Sagrado. México: Fondo de Cultura Económica, 2004.

CALABRESE, O. A idade neobarroca. São Paulo: Martins Fontes; Lisboa: Edições 70, 1988.

DELEUZE, G. A dobra: Leibniz e o barroco. Campinas: Papirus, 1991. 
. Francis Bacon - Lógica da Sensação. Rio de Janeiro: Jorge Zahar Editor, 2007.

DIDI-HUBERMAN, Georges. Ante el tiempo. Argentina: Adriana Hidalgo editora S. A., 2006.

HAUSER, A. História social da literatura e da arte. São Paulo: Mestre Jou, 1982.

SANSEVERO, Angélica. Barroco - Percursos e Contrastes.Disponível em < http://www.revista.art.br/site-numero-08/apresentacao.htm>. Revista Digital Art\& - ISSN 1806-2962 - Ano V - Número 08 - Outubro de 2007. Acesso em 16 jul. 2008.

SARDUY, Severo. Escrito sobre um Corpo. São Paulo: Editora Perspectiva S.A., 1979.

WÖLFFLIN, H. Renascença e barroco. São Paulo: Perspectiva, 1989. . Conceitos fundamentais de História da Arte. São Paulo: MartinsFontes, 1984.

http://www.starnews2001.com.br/Aleijadinho/barroco_brasileiro.html.

http://www.starnews2001.com.br/Aleijadinho/sao-francisco.htm

http://www.starnews2001.com.br/Aleijadinho/ordem-terceira.html

http://www.starnews2001.com.br/Aleijadinho/ordem-terceira.html.

http://www.artchive.com/artchive/b/bernini/teresa.jpg

DAPesquisa, Florianópolis, v.3 n.5, p.225-237, 2008. 